Fei Yang, Zongwei Wang, Pengju Liu, Libing Guo and Dong Xian*

\title{
The crystal structure of dichlorido-bis(3-methyl- 3-imidazolium-1-ylpropionato- $\mathrm{K}^{2}$ )-cadmium(II), $\mathrm{C}_{14} \mathrm{H}_{20} \mathrm{CdCl}_{2} \mathrm{~N}_{4} \mathrm{O}_{4}$
}

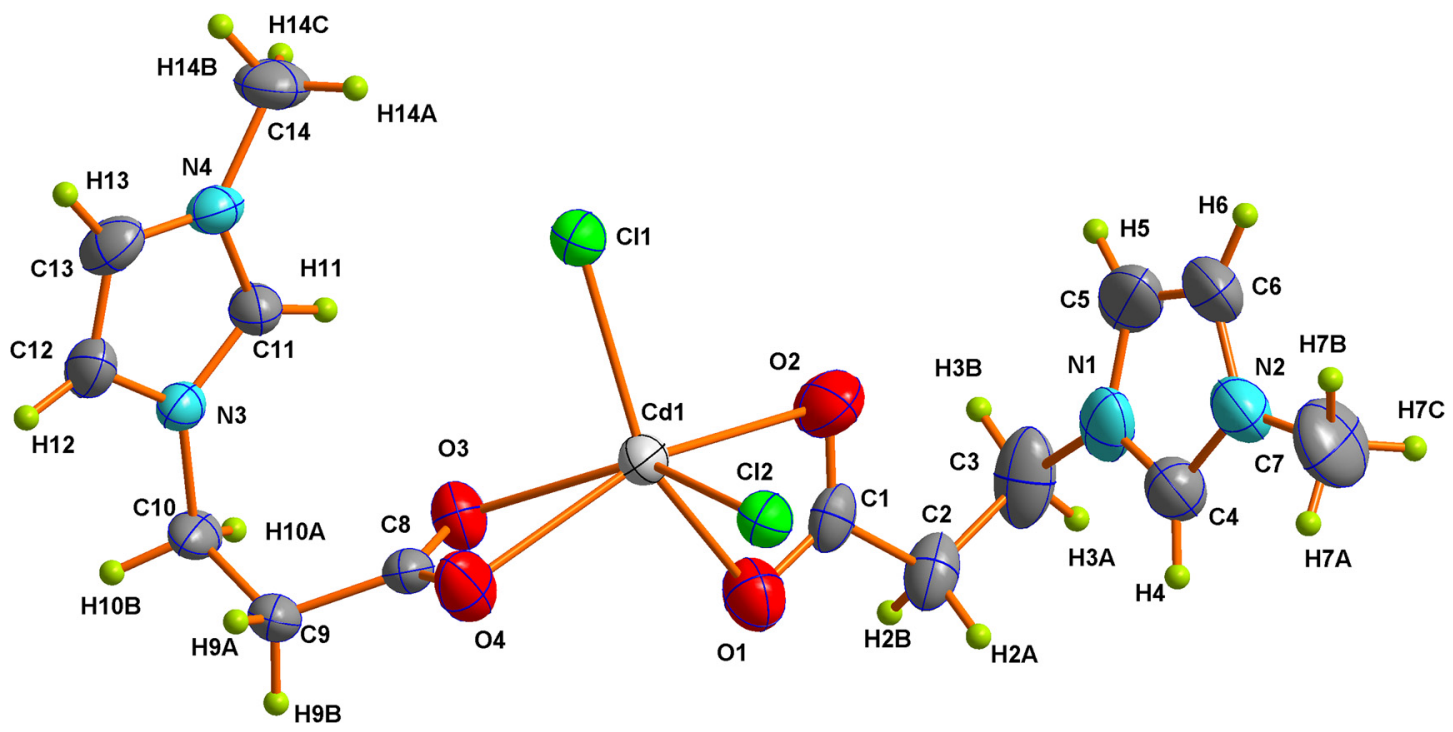

Figure 1: The asymmetric unit of the title compound, showing the atomic numbering scheme and $50 \%$ thermal displacement ellipsoids.

https://doi.org/10.1515/ncrs-2021-0238

Received June 8, 2021; accepted June 30, 2021;

published online July 14, 2021

\section{Abstract}

$\mathrm{C}_{14} \mathrm{H}_{20} \mathrm{CdCl}_{2} \mathrm{~N}_{4} \mathrm{O}_{4}$, monoclinic, $P 2_{1} / n$ (no. 14), $a=8.261(3) \AA$, $b=16.390(5) \AA, c=13.967(4) \AA, \quad \beta=95.850(4)^{\circ}$, $V=1881.3(10) \AA^{3}, Z=4, R_{g t}(F)=0.0342, w R_{r e f}\left(F^{2}\right)=0.0873$, $\mathrm{T}=296 \mathrm{~K}$.

*Corresponding author: Dong Xian, Henan Key Laboratory of Green Chemistry, Collaborative Innovation Center of Henan Province for Green Manufacturing of Fine Chemicals, Key Laboratory of Green Chemical Media and Reactions, Ministry of Education, School of Chemistry and Chemical Engineering, Henan Normal University, Xinxiang, 453007, P. R. China; and Institute of Chemistry, Henan Academy of Sciences, Zhengzhou, 450002, P. R. China,

E-mail: xxxiandong@sina.com. https://orcid.org/0000-0002-77754017

Fei Yang, Henan Key Laboratory of Green Chemistry, Collaborative Innovation Center of Henan Province for Green Manufacturing of Fine Chemicals, Key Laboratory of Green Chemical Media and Reactions, Ministry of Education, School of Chemistry and Chemical Engineering, Henan Normal University, Xinxiang, 453007, P. R. China; and Institute of Chemistry, Henan Academy of Sciences, Zhengzhou, 450002, P. R. China

Zongwei Wang, Pengju Liu and Libing Guo, Institute of Chemistry, Henan Academy of Sciences, Zhengzhou, 450002, P. R. China
Table 1: Data collection and handling.

\begin{tabular}{ll}
\hline Crystal: & Colourless block \\
Size: & $0.22 \times 0.17 \times 0.14 \mathrm{~mm}$ \\
Wavelength: & Mo $K \alpha$ radiation $(0.71073 \AA$ A $)$ \\
$\mu:$ & $1.47 \mathrm{~mm}^{-1}$ \\
Diffractometer, scan mode: & Bruker APEX-II, $\varphi$ and $\omega$ \\
$\theta_{\text {max }}$, completeness: & $28.2^{\circ},>99 \%$ \\
$N(h k l)_{\text {measured }}, N(h k l)_{\text {unique }}, R_{\text {int }}:$ & $11546,4546,0.033$ \\
Criterion for $I_{\text {obs }}, N(h k l)_{\mathrm{gt}}:$ & $I_{\text {obs }}>2 \sigma\left(I_{\text {obs }}\right), 3991$ \\
$N(\text { param })_{\text {refined }}:$ & 228 \\
Programs: & Bruker [1], Diamond [2], \\
& Olex2 [3], SHELX [4, 5] \\
\hline
\end{tabular}

CCDC no.: 2088586

The molecular structure is shown in the figure. Table 1 contains crystallographic data and Table 2 contains the list of the atoms including atomic coordinates and displacement parameters.

\section{Source of material}

1-Carboxypropyl-3-methylimidazolium chloride was preprared according to the method reported in reference [6]. 
Table 2: Fractional atomic coordinates and isotropic or equivalent isotropic displacement parameters $\left(\AA^{2}\right)$.

\begin{tabular}{|c|c|c|c|c|}
\hline Atom & $x$ & $y$ & $z$ & $U_{\text {iso }}{ }^{*} / U_{\text {eq }}$ \\
\hline d1 & $0.36826(2)$ & $0.41374(2)$ & $0.72343(2)$ & $0.03501(8)$ \\
\hline $\mathrm{Cl} 1$ & $0.12093(10)$ & $0.40598(6)$ & $0.61162(6)$ & $0.0584(2)$ \\
\hline $\mathrm{Cl} 2$ & $0.34017(10)$ & $0.32000(5)$ & $0.86133(6)$ & 0.05264 (19) \\
\hline 01 & $0.5275(3)$ & $0.50502(14)$ & $0.81420(17)$ & $0.0569(5)$ \\
\hline 02 & $0.2781(3)$ & $0.54916(17)$ & $0.79662(18)$ & $0.0660(6)$ \\
\hline 03 & $0.5341(3)$ & $0.43552(13)$ & $0.59840(15)$ & $0.0466(5)$ \\
\hline 04 & $0.5602(3)$ & $0.31500(15)$ & $0.66451(15)$ & $0.0581(6)$ \\
\hline N1 & $0.2213(4)$ & $0.64819(16)$ & 0.97288 (19) & $0.0541(7)$ \\
\hline N2 & $0.1115(4)$ & $0.58717(17)$ & $1.0865(2)$ & $0.0576(7)$ \\
\hline N3 & $0.4894(2)$ & $0.35472(13)$ & $0.38931(14)$ & $0.0324(4)$ \\
\hline N4 & $0.2300(3)$ & $0.35335(14)$ & $0.35552(15)$ & $0.0371(5)$ \\
\hline $\mathrm{C} 1$ & $0.4205(4)$ & $0.55538(17)$ & $0.83167(18)$ & $0.0406(6)$ \\
\hline $\mathrm{C} 2$ & $0.4742(4)$ & $0.6253(2)$ & 0.8971 (2) & $0.0525(8)$ \\
\hline $\mathrm{H} 2 \mathrm{~A}$ & 0.521776 & 0.603252 & 0.957948 & $0.063^{*}$ \\
\hline $\mathrm{H} 2 \mathrm{~B}$ & 0.558945 & 0.655075 & 0.868729 & $0.063^{*}$ \\
\hline $\mathrm{C} 3$ & $0.3429(6)$ & $0.6845(2)$ & $0.9168(3)$ & $0.0696(11)$ \\
\hline $\mathrm{H} 3 \mathrm{~A}$ & 0.391937 & 1001 & 0.951558 & $0.084^{\star}$ \\
\hline H3B & 0.289446 & 0.704124 & 0.856117 & $0.084^{*}$ \\
\hline $\mathrm{C} 4$ & $0.2506(4)$ & $0.6092(2)$ & $1.0553(2)$ & $0.0514(7)$ \\
\hline H4 & 353338 & 0.598749 & 1.086551 & $0.062^{\star}$ \\
\hline C5 & $0.0562(5)$ & $0.6508(3)$ & $0.9515(3)$ & $0.0815(14)$ \\
\hline H5 & .000868 & 674944 & 0.897502 & $0.098^{\star}$ \\
\hline C6 & $-0.0108(5)$ & $0.6131(3)$ & $1.0212(3)$ & $0.0793(13)$ \\
\hline H6 & -0.121627 & 0.605713 & 1.024838 & $0.095^{\star}$ \\
\hline C7 & $0.0913(5)$ & $0.5464(3)$ & 1.1759 (3) & $0.0845(13)$ \\
\hline $\mathrm{H} 7 \mathrm{~A}$ & 0.185528 & 3569 & 1.194580 & $0.127^{\star}$ \\
\hline H7B & -0.003391 & 0.512136 & 1.167737 & $0.127^{\star}$ \\
\hline $\mathrm{H} 7 \mathrm{C}$ & 078337 & 6215 & 4903 & $.127^{\star}$ \\
\hline $\mathrm{C} 8$ & $0.5920(3)$ & $0.36456(17)$ & $0.60168(18)$ & $0.0358(5)$ \\
\hline C9 & 0.6999 (3) & 0.339 & 0.526 & $0.0397(6)$ \\
\hline H9A & 0.694969 & 280813 & .519017 & $0.048^{\star}$ \\
\hline $\mathrm{H} 9 \mathrm{~B}$ & 0.811397 & 0.354089 & 0.548466 & $0.048^{\star}$ \\
\hline C10 & 0.6534 (3) & 0.37900 (19) & $0.43023(19)$ & $0.0395(6)$ \\
\hline $\mathrm{H} 10 \mathrm{~A}$ & 0.657303 & 0.437846 & 0.437519 & $0.047^{\star}$ \\
\hline $\mathrm{H} 10 \mathrm{~B}$ & 0.731547 & 0.363611 & 0.386154 & $0.047^{*}$ \\
\hline C11 & $0.3528(3)$ & $0.39343(17)$ & $0.40132(19)$ & $0.0374(5)$ \\
\hline H11 & 0.344534 & 0.441215 & 0.436400 & $0.045^{\star}$ \\
\hline C12 & $0.4517(4)$ & $0.28708(18)$ & $0.3345(2)$ & $0.0442(6)$ \\
\hline H12 & 0.524827 & 0.248683 & 0.315369 & $0.053^{\star}$ \\
\hline C13 & $0.2900(4)$ & 0.28630 (19) & $0.3134(2)$ & $0.0476(7)$ \\
\hline H13 & 0.229809 & 0.247287 & 0.276883 & $0.057^{\star}$ \\
\hline C14 & $0.0591(3)$ & $0.3768(2)$ & $0.3519(3)$ & $0.0565(8)$ \\
\hline $\mathrm{H} 14 \mathrm{~A}$ & 0.023388 & 0.371869 & 0.414962 & $0.085^{\star}$ \\
\hline H14B & -0.005036 & 0.341607 & 0.308095 & $0.085^{\star}$ \\
\hline $\mathrm{H} 14 \mathrm{C}$ & 0.046538 & 0.432236 & 0.330367 & $0.085^{\star}$ \\
\hline
\end{tabular}

CdO (1 mmol) with an excess of 1-carboxypropyl3-methylimidazolium chloride $(1.5 \mathrm{mmol})$ were added into a methanol-water (1:1) mixture $(20 \mathrm{~mL})$. This mixture was stirred for $24 \mathrm{~h}$ at $353 \mathrm{~K}$. After slow evaporation of the filtrate for one week at room temperature, colorless block crystals were obtained.

\section{Experimental details}

All hydrogen atoms were refined using riding coordinates with $U_{\text {iso }}(\mathrm{H})=1.2 U_{\text {eq }}(\mathrm{C})$, whereas the methyl hydrogen atoms were placed in the best location with $U_{\text {iso }}(\mathrm{H})=1.5 U_{\text {eq }}(\mathrm{C})$.

\section{Comment}

$\mathrm{COOH}$-functional ionic liquids have been designed, synthesized and explored in various applications such as separation and extraction $[7,8]$, catalysis $[9,10]$ and ionic liquid-based scavenger [11] and so on. Recently, some of them have also been utilized to construct coordination compounds [12, 13]. For example, Han et al. [12] reported the first example of lanthanide coordination frameworks, and demonstrated that the introduction of a functional group opens up new possibilities in crystal engineering and the material fabrication.

Due to the limited investigation on $\mathrm{COOH}$-functional ionic liquids, we used the prepared carboxypropyl3-methylimidazolium chloride to directly react with CdO, and obtained a mononuclear Cd(II) coordination compound, which is different to the one-dimensional polymeric structure obtained from ionic liquid 1-carboxymethyl-3-methylimidazolium chloride and $\mathrm{Cd}(\mathrm{OH})_{2}[14]$.

Structural representation and the atom numbering scheme of the title compound are provided in Figure 1. The asymmetric unit of the title structure consists of one $\mathrm{Cd}^{2+}$ cation, two neutral 3-methyl-3-imidazolium-1-ylpropionate ligands and two chloride ligands. The central metal ion Cd(II) attains a strongly distorted octahedral geometry. Here the equatorial plane is formed by three oxygen atoms of two organic ligands and one $\mathrm{Cl}^{-}$anion, while the axial positions are respectively occupied by another $\mathrm{Cl}^{-}$anion and the remaining coordinated $\mathrm{O}$ atom of one organic ligand. The bond distances of $\mathrm{Cd}-\mathrm{O}$ [2.288 (2)-2.585 (3) Å] and Cd-Cl [2.4452 (9)-2.4930 (9) Å] fall in the desired ranges. The alkyl chain is nearly vertical to the imidazole ring plane $86.7^{\circ}$, similar to that of zwitterionic compound [15] and salt with $\mathrm{Cl}^{-}$[15], and $\mathrm{PF}_{6}^{-}$[6], and TFSI $^{-}$[6]. This monomer units are further connected by numerous $\mathrm{C}-\mathrm{H} \cdots \mathrm{O}, \mathrm{C}-\mathrm{H} \cdots \mathrm{C}$ and $\mathrm{C}-\mathrm{H} \cdots \mathrm{Cl}$ weak hydrogen bonding interactions.

Author contributions: All the authors have accepted responsibility for the entire content of this submitted manuscript and approved submission. 
Research funding: The Special Scientific Research Projects of the Henan Academy of Sciences (210403019) is gratefully acknowledged.

Conflict of interest statement: The authors declare no conflicts of interest regarding this article.

\section{References}

1. Bruker. SAINT and SADABS; Bruker AXS Inc.: Madison, WI, USA, 2009.

2. Brandenburg K. DIAMOND. Visual Crystal Structure Information System. Version 3.2i; Crystal Impact: Bonn, Germany, 2012.

3. Dolomanov O. V., Bourhis L. J., Gildea R. J., Howard J. A. K., Puschmann H. OLEX2: a complete structure solution, refinement and analysis program. J. Appl. Crystallogr. 2009, 42, 339-341.

4. Sheldrick G. M. A short history of SHELX. Acta Crystallogr. 2008, A64, 112-122.

5. Sheldrick G. M. SHELXTL - Integrated space-group and crystalstructure determination. Acta Crystallogr. 2015, A71, 3-8.

6. Xuan X.-P., Chang L.-L., Zhang H., Wang N., Zhao Y. Hydrogen bonds in the crystal structure of hydrophobic and hydrophilic $\mathrm{COOH}$-functionalized imidazolium ionic liquids. CrystEngComm 2014, 16, 3040-3046.

7. Chen Y. H., Wang H. Y., Pei Y. C., Wang J. J. Selective separation of scandium (III) from rare earth metals by carboxyl-functionalized ionic liquids. Separ. Purif. Technol. 2017, 178, 261-268.

8. Ao Y. Y., Chen J., Wang Y., Chen H. B., Li J. Q., Zhai M. L. Radiation effect of carboxyl-functionalized task-specific ionic liquids on
$\mathrm{UO}_{2}{ }^{2+}$ removal: experimental study with DFT validation. J. Phys. Chem. B 2017, 121, 1893-1899.

9. Albert-Soriano M., Pastor I. M. Metal-organic framework based on copper and carboxylate-imidazole as robust and effective catalyst in the oxidative amidation of carboxylic acids and formamides. Eur. J. Org Chem. 2016, 2016, 5180-5188.

10. Albert-Soriano M., Trillo P., Soler T., Pastor I. M. Versatile barium and calcium imidazolium-dicarboxylate heterogeneous catalysts in quinoline synthesis. Eur. J. Org Chem. 2017, 2017, 6375-6381.

11. Cai Y., Zhang Y., Peng Y., Lu F., Huang X., Song G. Carboxylfunctional ionic liquids as scavengers: case studies on benzyl chloride, amines, and methanesulfonyl chloride. J. Comb. Chem. 2006, 8, 636-638.

12. Han L., Zhang S., Wang Y., Yan X., Lu X. A strategy for synthesis of ionic metal-organic frameworks. Inorg. Chem. 2009, 48, 786-788.

13. You L.-X., Guo Y., Xie S.-Y., Wang S.-J., Xiong G., Dragutan I., Dragutan V., Ding F., Sun Y.-G. Synthesis, structure and luminescence of lanthanide coordination polymers based on the 1,3-Bis(carboxymethyl) imidazolium salt. J. Solid State Chem. 2019, 278, 120900.

14. Guo H. M., Xian H. D., Zhang J., Ying T. K., Zhao G. L. Synthesis and crystal structure of a chlorine-bridged $\mathrm{Cd}(\mathrm{II})$ polymer with onedimensional polymeric structure: $\left[\mathrm{Cd}_{2}\left(\mathrm{C}_{6} \mathrm{H}_{8} \mathrm{~N}_{2} \mathrm{O}_{2}\right)_{2} \mathrm{Cl}_{4}\right]_{n} \cdots 3 n \mathrm{H}_{2} \mathrm{O}$. Chin. J. Inorg. Chem. 2008, 24, 1709-1712.

15. Braun D. E., Lampl M., Wurst K., Kahlenberg V., Griesser U. J., Schottenberger H. Computational and analytical approaches for investigating hydrates: the neat and hydrated solid-state forms of 3-(3-methylimidazolium-1-yl)propanoate. CrystEngComm 2018, 20, 7826-7837. 